\title{
Management of Groin Pseudoaneurysms: Indications and Outcomes for Thrombin Injection vs. Surgical Treatment
}

\section{Horn $\mathbf{M}^{1 *}$, Stahlberg $E^{2}$, Goltz JP², Rodd $C^{1}$, Ellebrecht $D^{1}$, Keck T1 and Kleemann $\mathbf{M}^{1}$}

${ }^{1}$ Division of Vascular and Endovascular Surgery, Department of Surgery, University Hospital Schleswig-Holstein Campus Lübeck, Ratzeburger Allee 160, 23538 Lübeck, Germany

${ }^{2}$ Department of Radiology and Nuclear Medicine, University Hospital Schleswig-Holstein Campus Lübeck, Ratzeburg-er Allee 160, 23538 Lübeck, Germany

\begin{abstract}
Objectives: Persistent pseudoaneurysm of the groin is a complication related to arterial puncture following invasive diagnostic and interventional procedures. This study reports our single center results for both surgical treatment and thrombin injection (TI).

Materials and Methods: In the period between January 2006 and December 2014, we analysed those patients who underwent invasive treatment for infra-inguinal pseudoaneurysm at our University Hospital. Patients for whom com-pression therapy had proven unsuccessful or was contraindicated were referred for invasive treatment. Patients with ruptured pseudoaneurysm and haemodynamic instability or infected pseudoaneurysm were treated surgically and therefore excluded from this analysis.

Results: A total of 105 patients with pseudoaneurysm were identified. The mean age of all patients (50 male, 55 female) was 72.1 ([SD] \pm 11.5 years. At the time of puncture, most patients $(95.3 \%)$ were taking either antiplatelet or anticoagulant medication. 57 of the 105 patients were treated by thrombin injection. The other 48 patients underwent surgical repair. Indications for surgical treatment were; large hematomata with neurological symptoms, vein compres-sion or severe pain. Thrombin injection shows a high success rate of $91.2 \%$. The majority of patients $(96.5 \%)$ required only one attempt of $\mathrm{TI}$ for aneurysm closure. Two embolic events occurred following $\mathrm{TI}$ and needed surgical revision. Overall complication rate of thrombin injection was $8.8 \%$. Surgical repair was successful in every patient but associated with high complication rates compared to $\mathrm{TI}(33.3 \%, \mathrm{p}=0.003)$. The mean pseudoaneurysm diameter for patients who underwent surgery was larger compared to those who were treated with $\mathrm{Tl}$ (surgery $=64.4$ $\mathrm{mm} \mathrm{SD} \pm 40.7, \mathrm{Tl}=34.9 \mathrm{~mm} \mathrm{SD} \pm 15.8 \mathrm{~mm}, \mathrm{p}=0.001$ ).
\end{abstract}

Conclusions: Thrombin injection is less invasive, results in lower complication rates and reduced hospital stay compared to open surgical repair of pseudoaneurysms. Nevertheless there is still indication for surgical treatment in symptomatic and large pseudoaneurysms.

Keywords: Pseudoaneurysm; False aneurysm; Endovascular complication; Thrombin injection; Operation of the groin

Abbreviations: SD: Standard Deviation; Min: Minimum; Max: Maximum; CFA: Common Femoral Artery; SFA: Superficial Femoral Artery; DFA: Deep Femoral Artery; EIA: External Iliac Artery; ASA: Acetyl Salicylic Acid; AOD: Arterial Occlusive Disease; COPD: Chronic Obstructive Pulmonary Disease; CTA: Computed Tomographic Angiography; INR: International Normalised Ratio; MRI: Magnetic Resonance Imaging; TI: Thrombin Injection; IU: International Units; i.v.: intra venous; TAVI: Transcatheter Aortic Valve Implantation; PTT: Partial Thromboplastin Time; F: French (size of sheet)

\section{Introduction}

Pseudoaneurysm (synonym: false aneurysm) is defined as a contained pulsatile hematoma of an artery with disruption of all layers (intima, media, adventitia) which is surrounded by tissue. The reported incidence following arterial catheterization ranges from $0.05 \%$ to $2 \%$ in diagnostic procedures and increases up to $2 \%$ to $6 \%$ in endovascular treatment [1]. Pseudoaneurysms may cause serious complications, for example local skin ischaemia with resulting necrosis, pain, infection, compression of neighbouring structures, such as blood vessels (venous thrombosis) and nerves (nerve lesions), distal embolism, and rupture with life-threatening bleeding [2]. Prompt diagnosis and choice of appropriate treatment are therefore of great importance. In addition to surgery, there are known non-invasive and minimally invasive methods for treating pseudoaneurysm. The most commonly used of these at present is ultrasound-guided compression therapy [3]. Other methods include non-ultrasound-guided compression (manual or external compression devices, e.g., FemoStop ${ }^{\oplus}$-system), endovascular stentgraft implantation, coil embolisation, and injection of $0.9 \%$ saline solution alongside the neck of the pseudoaneurysm. However, these methods are currently rarely used [3-5]. In recent years a large number of studies have found duplex ultrasound-guided percutaneous Thrombin injection [TI] to be a safe and effective alternative to surgery or compression therapy. This clinical study documents our single centre experience in the treatment of pseudoaneurysm by either ultrasoundguided TI or surgery.

${ }^{*}$ Corresponding author: Dr. Marco Horn, Division of Vascular and Endovascular Surgery, Department of Surgery, University Hospital Schleswig-Holstein Campus Luebeck, Ratzeburger Allee 160, 23538 Lübeck, Germany, Tel: 0451 500-47010; E-mail: marco.horn@uksh.de

Received January 21, 2017; Accepted February 17, 2017; Published February 24,2017

Citation: Horn M, Stahlberg E, Goltz JP, Rodd C, Ellebrecht D, et al. (2017) Management of Groin Pseudoaneurysms: Indications and Outcomes for Thrombin Injection vs. Surgical Treatment. J Vasc Med Surg 5: 300. doi: 10.4172/2329 6925.1000300

Copyright: (c) 2017 Horn M, et al. This is an open-access article distributed under the terms of the Creative Commons Attribution License, which permits unrestricted use, distribution, and reproduction in any medium, provided the original author and source are credited. 
Citation: Horn M, Stahlberg E, Goltz JP, Rodd C, Ellebrecht D, et al. (2017) Management of Groin Pseudoaneurysms: Indications and Outcomes for Thrombin Injection vs. Surgical Treatment. J Vasc Med Surg 5: 300. doi: 10.4172/2329-6925.1000300

\section{Material and Methods}

We retrospectively analysed all patients invasively treated (operation or TI) for pseudoaneurysm between January 2006 and December 2010. From January 2011 to December 2014 we prospectively recorded the data for every patient who diagnosed with an infra-inguinal pseudoaneurysm. Patient documentation included demographic data; anticoagulant therapy; concomitant diseases; multi-morbidity (defined as being affected by 2 or more chronic diseases [6]) cause and time of appearance of the pseudoaneurysm; time of diagnosis; diagnostic procedures; initial treatment; size, form, and site of the pseudoaneurysm; treatment methods used, hospital stay and complications. Patients in whom compression therapy had proved unsuccessful or was contraindicated were referred for invasive treatment. Patients with active bleeding and haemodynamic instability or infected pseudoaneurysms were treated immediately by surgery and excluded from this analysis.

\section{Percutaneous thrombin injection}

The pseudoaneurysm is first investigated with duplex sonography to demonstrate the structure, size, and anatomical relationships. Tangential vascular injuries and arteriovenous fistulae should be definitively excluded. Using an aseptic field, the pseudoaneurysm is punctured with a freehand technique and ultrasound control. Sonographic visualization of the needle tip is essential to avoid complications. In the case of loculated pseudoaneurysms or poor image quality, it can be difficult to position the needle tip in the middle of the aneurysm. Placement in or near the neck is consciously avoided in order to minimise the risk of arterial embolism following the injection of the thrombin solution. Should image quality be poor, injection of saline solution $(0.9 \%)$ results in turbulence within the pseudoaneurysm that is clearly visible in native ultrasound images and gives additional security for needle placement before injecting thrombin. The thrombin [Human thrombin (lyophilised thrombin solution, $500 \mathrm{IU}$ ) in calcium chloride $(1 \mathrm{~mL})$ from Tissucol-Kit ${ }^{\circledR}$ (Baxter, Unterschleissheim, Germany)] injection is given slowly with duplex ultrasound guidance until blood flow within the aneurysm ceases (Figure 1). Oscillatory flow in the neck is tolerated. Embolism is definitively excluded by immediate duplex ultrasound of the inguinal and peripheral vessels and then again 24 hours after the procedure. The patients are fully mobilised after two hours of bed rest and no additional pressure bandage used.

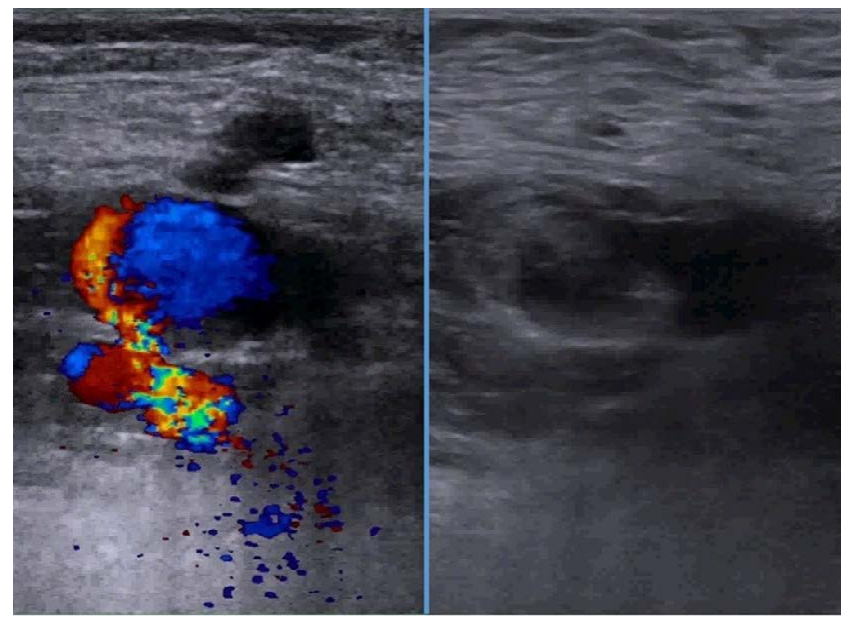

Figure 1: Pseudoaneurysm of the deep femoral artery (left). Thrombosed Pseudoaneurysm following Thrombin injection (right).

\section{Operative procedure}

All cases with large haematoma and pain, neurological symptoms, compression of the deep vein or compartment syndrome undergo surgery as first line treatment, under general anaesthesia. The femoral bifurcation is exposed via standard transinguinal approach, systemic heparin is administered and the vessels clamped. The puncture site is either repaired by primary closure or, in cases with significant vessel disruption the vessel is reconstructed by patch-plasty using bovine pericardium or interposition grafting. Blood flow is checked immediately by means of intraoperative continuous wave Doppler ultrasound.

\section{Statistical methods}

Statistical analysis and data presentation were carried out using SPSS 22.0 for Windows (SPSS, IBM Corp.). Descriptive statistics were produced using means, medians, ranges and standard deviations for continuous variables, and percentages for categorical variables. The $\mathrm{X}^{2}$ test or exact Fisher test were used to compare percentages, and Student $\mathrm{t}$ test or non-parametric tests were used to compare mean values. Statistical significance was evaluated at the $5 \%(\alpha=0.05)$ level.

\section{Results}

A total of 105 patients with pseudoaneurysm were included in the analysis. Of these, 57 were primarily treated by means of TI and 48 underwent elective operation. The mean age of all patients (50 male, 55 female) was 72.1 years $(\mathrm{SD} \pm 11.5$, median $=74.0, \min =31$, $\max =91$ ). Pre-existing conditions present in the patients are listed in Table 1. The Group of TI showed no significant difference in multi-morbiditiy compared to the group of operation ( $\mathrm{TI}=93.0 \%, \mathrm{OP}=85.4 \%, \mathrm{p}=0.173$ ). Most patients $(95.3 \%)$ had antiplatelet or anticoagulation medication at the time of puncture (Table 2$)$. Only a few patients $(n=5)$ had received no antiplatelet or anticoagulant therapy. One patient suffered from mild-haemophilia A. Another patient developed a pseudoaneurysm after thrombolysis therapy. In 16 of 105 patients (15.2\%) an activeclosure device was used after catheterization for haemostasis. The most common procedure causing pseudoaneurysm in our study sample were coronary angiography (67.6\%), followed by endovascular ilio-femoral procedures (Table 3 ). The common femoral artery (CFA) was the most common location of pseudoaneurysm (67 patients, 63.8\%). In $34.3 \%$

\begin{tabular}{|c|c|c|c|}
\hline Pre-existing disease & Number (n) & Operation & Thrombin \\
\hline Hypertension & 101 & 46 & 55 \\
\hline Coronary heart disease & 87 & 38 & 49 \\
\hline $\begin{array}{l}\text { Chronic obstructive pulmonary } \\
\text { disease }\end{array}$ & 17 & 6 & 11 \\
\hline Peripheral arterial occlusive disease & 33 & 9 & 24 \\
\hline Diabetes mellitus & 25 & 7 & 18 \\
\hline Renal failure requiring dialysis & 5 & 4 & 1 \\
\hline
\end{tabular}

Table 1: General pre-existing diseases.

\begin{tabular}{|c|c|c|}
\hline & Number & \% \\
\hline Antiplatelet Therapy & $\mathbf{8 0}$ & $\mathbf{7 6 . 2}$ \\
\hline Double antiplatelet therapy & 34 & 32.4 \\
\hline Antiplatelet plus low molecular heparin & 29 & 27.6 \\
\hline Antiplatelet plus anticoagulation & 6 & 5.7 \\
\hline Oral anticoagulation (alone) & $\mathbf{1 3}$ & $\mathbf{1 2 . 4}$ \\
\hline Coumarin type anticoagulation & 10 & 9.5 \\
\hline New oral anticoagulation & 3 & 2.9 \\
\hline Low molecular heparin (alone) & $\mathbf{7}$ & $\mathbf{6 . 7}$ \\
\hline
\end{tabular}

Table 2: Medication to compromising coagulation system. 
Citation: Horn M, Stahlberg E, Goltz JP, Rodd C, Ellebrecht D, et al. (2017) Management of Groin Pseudoaneurysms: Indications and Outcomes for Thrombin Injection vs. Surgical Treatment. J Vasc Med Surg 5: 300. doi: 10.4172/2329-6925.1000300

Page 3 of 7

(36 patients) the puncture site was located to distal (superficial femoral artery $S F A=22$ patients, deep femoral artery $D F A=12$ patients, SFA and $\mathrm{DFA}=2$ ). The iliac external artery was the site of pseudoaneurysm in 2 patients. Sheet size during puncture did not differ between both groups (surgery=6.45 F SD $\pm 1.46 ; \mathrm{TI}=7.23 \mathrm{~F} \mathrm{SD} \pm 2.62$; median $=6, \mathrm{p}=0.071$ ).

The pre-, peri-, and postoperative data from the patients who underwent either operation or percutaneous TI are summarised in Table 4.

\section{Diagnostic workup and patient selection}

In 96 of 105 patients the diagnosis was primarily made by duplex sonography. In the other 9 patients diagnosis was based on clinical evaluation and confirmed by ilio-femoral computed tomographic angiography (CTA) to exclude retroperitoneal bleeding (Figure 2). Sixty-one of the 105 patients had undergone unsuccessful ultrasoundguided compression therapy. 26 patients were selected for primary TI without having undergone compression therapy. The reasons for this were pain on attempted compression; incipient skin destruction;

\begin{tabular}{|c|c|c|c|}
\hline \multicolumn{2}{|c|}{ Cause of PA } & \multirow{2}{*}{$\begin{array}{c}\mathbf{n} \\
71\end{array}$} & \multirow{2}{*}{$\begin{array}{c}\% \\
67.6\end{array}$} \\
\hline - & Coronary angiography & & \\
\hline - & Endovascular iliofemoral procedures & 18 & 17.1 \\
\hline • & Transcatheter aortic valve implantation (TAVI) & 6 & 5.7 \\
\hline - & Invasive arterial blood pressure monitoring & 2 & 1.9 \\
\hline - & Thrombolysis therapy (local) & 2 & 1.9 \\
\hline • & Carotid stent implantation & 2 & 1.9 \\
\hline - & Inaccurate insertion of temporary dialysis catheter & 2 & 1.9 \\
\hline - & Visceral arterial intervention (renal denervation) & 1 & 0.9 \\
\hline - & Watchman ${ }^{\circledast}$ implantation & 1 & 0.9 \\
\hline
\end{tabular}

Table 3: A wide range of causes for persistent PA. The common feature is the arterial puncture. high puncture site in conjunction with extreme obesity with no possibility of compression; and a coagulation disorder, namely mildhaemophilia A. 18 patients who had undergone neither compression therapy nor TI underwent primary operation. Two of these patients had been found to be unsuitable for compression therapy and had declined TI. One patient was primary treated by endovascular balloonocclusion which was unsuccessful and subsequently required surgery due to retroperitoneal haematoma and neurological deficit. The other patients were underwent primary surgery due to the presence of large haematomata with neurological symptoms, vein compression or severe pain.

\section{Thrombin injection}

Fifty-seven patients ( 24 male, 33 female, mean age 75.4 [SD \pm 9.9$]$ years, median 76 years) were treated by duplex ultrasound-guided TI. All patients were on anticoagulant or antiplatelet medication. The causal procedures were similar to patients treated by surgery and included

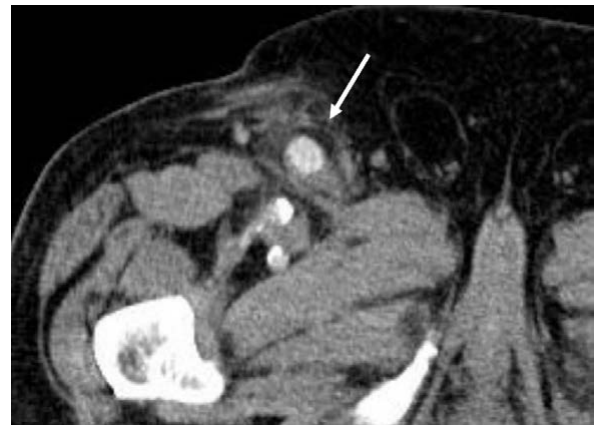

Figure 2: CTA is rarely used to confirm diagnosis of inguinal PA (arrow).

\begin{tabular}{|c|c|c|c|c|}
\hline \multirow{2}{*}{\begin{tabular}{|l|} 
Parameter \\
Age (years) \\
\end{tabular}} & & \multirow{2}{*}{$\begin{array}{c}\begin{array}{c}\text { Surgery } \\
(\mathbf{n = 4 8 )}\end{array} \\
68.3(\mathrm{SD} \pm 13.2)\end{array}$} & \multicolumn{2}{|c|}{$\begin{array}{l}\text { Thrombin injection } \\
(n=57)\end{array}$} \\
\hline & & & $75.4(\mathrm{SD} \pm 9.9)$ & \multirow[t]{2}{*}{$p=0.001$} \\
\hline Gender & & $m: 26, f: 22$ & $m: 24, f: 33$ & \\
\hline Multimorbidity & & $41(85.4 \%)$ & $53(93.0 \%)$ & $p=0.173$ \\
\hline Size $(\mathrm{mm})$ & & $64.4(\mathrm{SD} \pm 40.7)$ & $34.9(\mathrm{SD} \pm 15.8)$ & $p=0.001$ \\
\hline \multirow[t]{3}{*}{ Cause } & Coronary angiography & 38 & 33 & \\
\hline & Peripheral endovascular procedure & 5 & 13 & \\
\hline & Other & 5 & 11 & \\
\hline \multirow[t]{2}{*}{ Diagnosis } & Duplex sonography & 42 & 54 & \multirow[t]{2}{*}{$p=0.295$} \\
\hline & Computed tomography & 6 & 3 & \\
\hline \multicolumn{2}{|c|}{ Anticoagulants/Antiplatelets } & $43(90.0 \%)$ & $57(100 \%)$ & $p=0.176$ \\
\hline \multirow[t]{3}{*}{ Form } & Simple & 21 & 38 & \multirow[t]{3}{*}{$p=0.100$} \\
\hline & Loculated & 22 & 19 & \\
\hline & Not documented & 5 & 0 & \\
\hline \multirow[t]{3}{*}{ Puncture site } & Common femoral artery & 29 & 38 & \\
\hline & Distal (SFA, DFA) & 17 & 21 & \\
\hline & Proximal (External iliac artery) & 2 & 0 & \\
\hline \multicolumn{2}{|l|}{ Sheet size (F) } & $6.45(\mathrm{SD} \pm 1.46)$ & $7.23(\mathrm{SD} \pm 2.62)$ & $p=0.071$ \\
\hline \multicolumn{2}{|c|}{ Blood transfusion } & $14(29.2 \%)$ & 0 & $p=0.001$ \\
\hline \multicolumn{2}{|c|}{ Success rate $(\%)$} & 100 & 91.2 & $p=0.610$ \\
\hline \multirow[t]{6}{*}{ Complications } & Total & $16(33.3 \%)$ & $5(8.8 \%)$ & \multirow[t]{6}{*}{$p=0.003$} \\
\hline & Revision & 7 & 4 & \\
\hline & Embolism & l & 2 & \\
\hline & Wound healing disturbance (conservative) & 4 & 0 & \\
\hline & Death & 0 & 1 & \\
\hline & Other & 5 & 0 & \\
\hline \multicolumn{2}{|c|}{ Hospital stay (days) } & $10,7(\mathrm{SD} \pm 9.9)$ & $6,5(S D \pm 9,4)^{d}$ & $p=0.04$ \\
\hline
\end{tabular}

Table 4: Pre-, peri-, postoperative and interventional data. 
Citation: Horn M, Stahlberg E, Goltz JP, Rodd C, Ellebrecht D, et al. (2017) Management of Groin Pseudoaneurysms: Indications and Outcomes for Thrombin Injection vs. Surgical Treatment. J Vasc Med Surg 5: 300. doi: 10.4172/2329-6925.1000300

Page 4 of 7

coronary angiography $(\mathrm{n}=33)$, peripheral endovascular procedures $(\mathrm{n}=13)$, transcatheter aortic valve implantation (TAVI) $(\mathrm{n}=6)$, carotid stent implantation $(n=1)$, peripheral thrombolytic therapy $(n=1)$, arterial puncture for invasive blood pressure measurement $(n=1)$, renal denervation $(\mathrm{n}=1)$ and Watchman ${ }^{\circ}$ implantation (left atrial appendage closure device, $\mathrm{n}=1$ ). In 38 patients duplex ultrasound showed a simple pseudoaneurysm, while 19 patients were found to have a loculated, complex pseudoaneurysm. Mean pseudoaneurysm diameter was 34.9 $\mathrm{mm}(\mathrm{SD} \pm 15.8 \mathrm{~mm})$, while the largest had a maximum diameter of 72 $\mathrm{mm}$. The dose of thrombin solution injected differed between cases: mean dose of thrombin $=343.1$ I.U. SD \pm 193.0 ; minimum dose $=50$ I.U., maximum dose $=800$ I.U. and never exceeded $2 \mathrm{~mL}$ (1000 I.U.). TI was successful in 52 patients (success rate 91.2\%). Two patients required further TI to successfully treat the pseudoaneurysm without complication. In five patients TI failed for various reasons. One patient in whom TI failed had mild-haemophilia A. After unsuccessful TI this patient underwent operation. Two patients had recurrent pseudoaneurysm after TI, but were subsequently successfully treated by duplex-guided compression therapy. One patient with a large pseudoaneurysm (72 mm maximum Diameter) required multiple treatments: including initial compression therapy, followed by TI, attempted endovascular balloon occlusion and eventually proceeded to emergency surgery for active bleeding. In another patient TI was technically successful but with an embolic complication of the lower limb. In this case, the subsequent thrombolytic therapy actually caused recurrent pseudoaneurysm with rapid progression and operation was necessary. There were no infective or allergic complications. In one patient who had undergone successful TI, surgical evacuation of a haematoma had to be performed due to compression of the common femoral vein and consequent risk of thrombosis. Two embolic complications occurred following TI in both cases required surgical thrombectomy. One critically ill patient died one day after successful TI on intensive care unit due to heart failure. There was no evidence that this complication was due to TI. Mean length of postinterventional hospital stay was 6.5 days ( $\mathrm{SD} \pm 9.4$, median 2.5 ) but was not determined by the intervention itself, but by the underlying disease.

\section{Surgical treatment}

In 48 patients ( 26 male, 22 female) the pseudoaneurysm was treated surgically without proceding TI. Patients who underwent surgery were younger compared to the TI group (mean age $=68.3$ years, $\mathrm{SD} \pm 13.2$, median $71.5, \mathrm{p}=0.001$ ). At time of diagnosis 43 of the 48 patients were receiving anticoagulant or antiplatelet medication. Twenty-one of the pseudoaneurysms were non-loculated (simple) and 22 were loculated (complex), while the remainder $(n=5)$ were not definitively classified. Mean aneurysm diameter was significantly larger compared to the TI group (surgery=64.4 mm SD \pm 40.7 median $57 \mathrm{~mm}$; TI $=34.9 \mathrm{~mm}$ $\mathrm{SD} \pm 15.8$, median $33 \mathrm{~mm} ; \mathrm{p}=0.001$ ). The operation was successful in all cases. In 46 patients the pseudoaneurysm could be repaired by simple suture of the arterial puncture (Figures 3-5), but one patient required patch angioplasty (bovine pericardium) and in another patient required reconstruction with graft interposition (Dacron, 8 $\mathrm{mm}$ diameter). Mean duration of operation was 72 minutes (SD \pm 49, median 59.5). Fourteen patients required peri-operative blood transfusion. Overall postoperative morbidity in surgical group was $33.3 \%(\mathrm{n}=16)$ and showed a significantly higher complication rate compared to the TI group (TI $\mathrm{n}=5, \mathrm{p}=0.003$ ). In 7 patients, surgical revision was required due to either postoperative haematoma or wound infection. Four patients developed wound healing problems which were managed conservatively. These four patients had previously

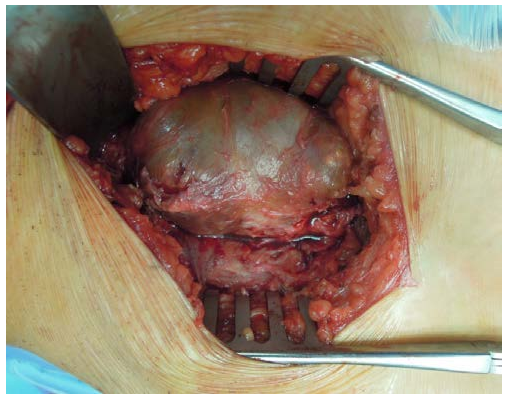

Figure 3: Surgical treatment by simple oversewing of a huge Pseudoaneruysma with maximum diameter of more than $90 \mathrm{~mm}$ : prepared pseudoaneurysm.

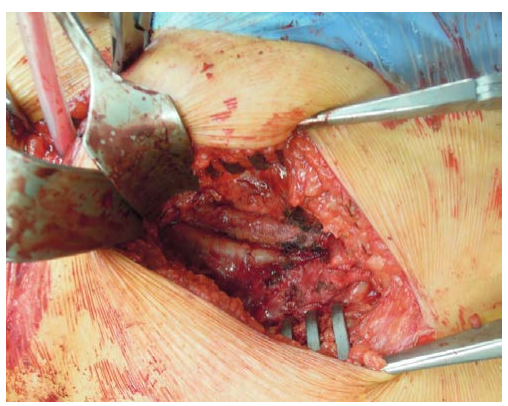

Figure 4: Surgical treatment by simple oversewing of a huge Pseudoaneruysma with maximum diameter of more than $90 \mathrm{~mm}$ : resection of pseudoaneurysm and simple suture of the arterial puncture site.

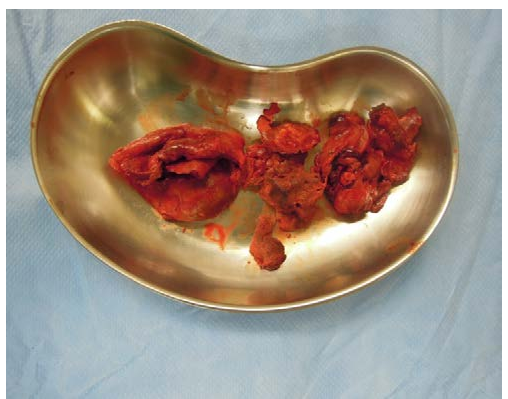

Figure 5: Surgical treatment by simple oversewing of a huge Pseudoaneruysma with maximum diameter of more than $90 \mathrm{~mm}$ : resected aneurysm capsula.

undergone unsuccessful compression therapy. Two patients developed haematomata that did not necessitate surgical revision. One patient was diagnosed by deep venous thrombosis on postoperative imaging which was probably caused by preoperative compression therapy. Two patients developed postoperative pneumonia with prolonged hospital stay and requiring treatment in intensive care. There were no deaths in the operative group. Mean postoperative hospital stay was longer compared to the TI group (surgery $=10.7$ days $\mathrm{SD} \pm 9.9$, median 6 , $\mathrm{p}=0.04)$. Analgesic medication was given for a mean period of 6.0 days $(\mathrm{SD} \pm 5.2$ days).

\section{Discussion}

Constantly increasing rates of arteriosclerotic disease and the associated advances in diagnosis and therapeutic endovascular techniques have led to an increase in the incidence of therapeutic transcutaneous arterial puncture [7]. Our data present invasive treatment of patients with persisting pseudoaneurysm of the groin 
following arterial puncture for wide a range of indications and a variety of departments, including cardiology, radiology, neuroradiology, nephrology, vascular surgery or intensive care medicine (Table 3).

The efficacy of aneurysm closure by TI in the observed study period was high (success rate 91.2\%), in line with the reported literature. In most studies, successful treatment by TI was accomplished in more than $90 \%$ of patients. Procedural success rates range between $79 \%$ and $99.6 \%$. Most authors report a repeated application of TI in 11 $\%$ to $15 \%$ of cases to achieve complete pseudoaneurysm obliteration $[1,8,9]$. In our sample, only 2 patients $(3.5 \%)$ received reapplication of TI for successful closure. From our experience with human thrombin only small quantities are required for the successful closure of pseudoaneurysm. TI with direct duplex ultrasound guidance reduces the required dose of injection solution. In our view the dose of 4000-8000 IU of thrombin used for simple PAs by a few authors cannot be justified [10]. The largest dose used in any of the cases reported here was $800 \mathrm{IU}$ of thrombin. As in other published studies, excellent results were obtained even in patients with antiplatelet or anticoagulation medication $[8,9,11]$. In cases requiring high thrombin doses, with no observed thrombosis of the pseudoaneurysm, the needle position should first be checked before proceeding. The need for postinterventional compression by means of a pressure bandage is disputed and clear recommendations are missing in the literature. We did not apply a pressure bandage, however this question should be decided on a case-by-case basis.

In the group of TI, 5 out of 57 (8.8\%) patients developed complications. One seriously ill patient died during the hospital stay from his underlying disease. There was no association between TI and cause of death. In two other patients pseudoaneurysm occlusion was not achieved by TI, so that ultimately an operation was necessary. One of these patients was known to have a coagulation disorder (mildhaemophilia A). The second patient had a huge pseudoaneurysm with maximum diameter of $72 \mathrm{~mm}$. In retrospect, this patient should have been treated surgically in the first instance due to the size of the aneurysm (see below). Arterial embolism occurred in 2 patients after TI (3.5\%) and both were treated surgically. Possible causes of embolism due to TI can only be hypothesised. In one case the thrombin was possibly injected too quickly, which increases the risk for embolism [12]. Therefore slow and fractionated injection of thrombin is recommended. Important factors contributing to avoid embolism were correct positioning of the injection needle in the centre of the aneurysm and use of a smaller dose of thrombin. Aspiration of blood does not prove that the needle is positioned in the pseudoaneurysm, as it can also occur if the needle is inside a blood vessel, in which case TI could cause serious complications. Definitive duplex ultrasound imaging of the needle tip is therefore essential. The second patient suffered from severe peripheral arterial occlusive disease and showed occlusion of his femoro-crural bypass after TI. Lewandowski described microembolisation occurring in 33 to $38 \%$ of patients due to thrombin injection [12]. A small embolism could induce vascular occlusion in those patients with pre-existing vascular disease. Special care should be taken in these patients. Vascular complications such as arterial thromboembolism and venous thrombosis have been reported in the literature as occurring after TI [13]. Overall complication rate after TI presented in the literature is $1.4 \%$ up to $4 \%$, which is usually defined as vascular or allergic complication. Surgical revision following unsuccessful TI is frequently not considered as complication by the most authors but ranges between $2,8 \%$ and $7.4 \%$ [1], [14,15]. Our defined complication rate of $8.8 \%$ includes direct vascular complications and unsuccessful treatment with subsequent requirement for surgical treatment and is comparable to the reported literature.

Surgery in pseudoaneurysm was highly successful, with no failed procedures or groin pseudoaneurysms recurrences. The literature does not report success rates because open exploration results in definitive localization of the pseudoaneurysm and repair. Finally there are no defined limitations to surgical treatment. There were no deaths in the operative group in our sample as compared with previously reported mortality rates of $3.8 \%$ to $7.9 \%$ [16]. The disadvantage of surgical treatment lies in the high rate of postoperative complications. In our sample, $33 \%$ of the patients developed postoperative complications, most of which related to wound healing, which is similar to that reported in other studies [16]. The apparently high rate of complications (33.3\%) in surgical patients is primarily considered to be caused by the severity of the disease in that negatively preselected patient cohort. Indications for surgery include hematoma-related skin maceration, compression of neighbouring structures, neurological symptoms, suspected local infection, rapidly expanding or very large pseudoaneurysms and failure of other therapeutic options. Similarly surgery should not be overlooked when there is a vital indication in case of bleeding or shock or when the puncture site is retroperitoneal [17]. This study sample shows three patients with retroperitoneal hematomata. As mentioned above, patients with infected pseudoaneurysms or active bleeding with shock were excluded from our analysis. Nevertheless, the surgical group showed a much larger pseudoaneurysm diameter $(64.4 \mathrm{~mm}, \mathrm{SD}$ $\pm 40.7 \mathrm{~mm}$ ) compared to the group of TI $(34.9 \mathrm{~mm}, \mathrm{SD} \pm 15.8 \mathrm{~mm})$. Moreover the occurrence of postoperative wound healing disturbances is partly attributable to skin maceration resulting from previously unsuccessful compression therapy. The four patients in the present series who developed a minor postoperative wound healing problems had previously undergone compression therapy. Multiple attempts of compression therapy should be avoided and account should be taken of the possible need for operation at a later date. We recommend a timely procedural change if compression therapy fails, e.g., thrombin injection.

Comparison of TI and surgery is limited by the absence of randomized data in our study. Even if age was different in both groups, age was not consciously taken into account in the indication setting. Localization, kind of arterial puncture and comorbidity were similar in both groups. Indications for surgical treatment were based on size and clinical symptoms as mentioned above. Patients who were treated surgically, had significantly larger pseudoaneuryms and higher preoperative risk factors of skin maceration, neurological symptoms or extensive pain. In most of these patients no alternative therapy was indicated. Furthermore, there exists a negative selection bias in both treatment groups compared with previous studies on thrombin injection. Patients with complex pseudoaneuryms were referred to our vascular unit from a variety of departments in our hospital. Therefore most patients had already had unsuccessful alternative therapy approaches (usually duplex guided compression-58.1\%) or had contraindications for non-invasive methods in the presented study sample. This negative selection must be taken into account when interpreting the data. Also for this reason, we do not present any incidence data that has already been published in other work [1]. However, surgical treatment resulted in a high complication rate and prolonged hospital stay as mentioned above. In view of the excellent results obtained with TI by the present and other working groups, the theoretical need for a randomised study can be ignored and TI should be performed first by absence of contraindications $[1,8,9]$. 
The increasing expertise acquired over the course of the study permitted a broadening of the indications for TI. Consequently, TI was successfully used for an increasing proportion of larger and loculated PAs, traditionally considered to be problematic. In the case of loculated (complex) pseudoaneurysms, the dose of thrombin should be reduced by administering the injection into the cavity that arises from the neck. Throughout the observed period, the number of patients treated by TI steadily increases whereas surgical procedures rather decreased or remain constant (Figure 6). Furthermore we detected an overall increase in invasive treatment. It remains unclear whether the number of complex pseudoaneurysms increased due to the expansion of endovascular therapies and led to rising incidence of invasive treatment. It is also conceivable that growing experience with TI and low complication rate even in patients with co-morbidities, resulted in a lower threshold for implementing this method. We even observed pseudoaneurysms at other locations e.g., brachial artery, which were treated with TI. Due to the small number of these cases, they were not considered in the present work.

The current guidelines of our department specify a large pseudoaneurysm diameter of more than $50 \mathrm{~mm}$ and a wide puncture channel of more than $4 \mathrm{~mm}$ as contraindications for TI. In these cases we recommend primary surgical treatment. For the length of the pseudoaneurysm neck we did not define exact exclusion criteria for TI but the neck should be clearly visible on ultrasound. Conservative surveillance can only be recommended for very small pseudoaneurysms (diameter $<2 \mathrm{~cm}$ ), as in such cases the likelihood that the pseudoaneurysm will undergo spontaneous thrombosis is very high [18]. Furthermore, for those patients under surveillance, modification of anticoagulation or antiplatelet therapy should be considered, particularly for patients on dual or triple therapy. The spontaneous evolution of larger pseudoaneurysms is essentially unpredictable, since no suitable duplex ultrasound criteria for prediction are available [19]. In view of the possibility of complications ambulant monitoring of patients with larger pseudoaneurysms cannot be recommended. All such patients should therefore be actively treated [4]. Ultrasoundguided compression therapy was not issue of this study but it is even a well-established and non-invasive procedure and should be attempted in the first instance in case of simple pseudoaneurysms with a long

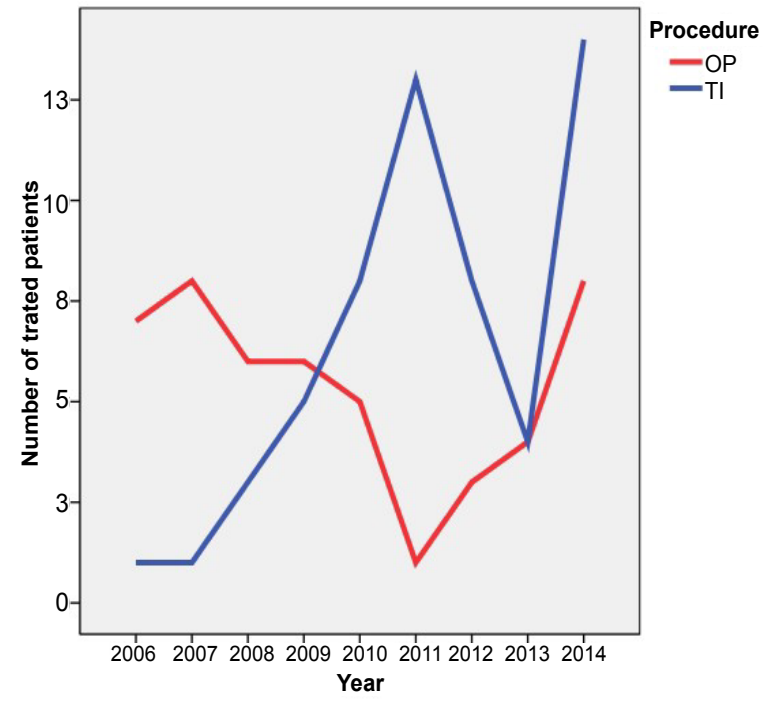

Figure 6: Increase of patient treatment by $\mathrm{TI}$ and proportionally decrease of surgical approach. Overall increase of invasive treatment. thin neck and moderate antiplatelet therapy. A significant risk of compression therapy is deep venous thrombosis or skin maceration which could be caused especially by repeated and non-duplex guided compression. For this reason, the authors do not recommend repetitive compressions or long term compression without ultrasound guidance following failure of compression, but advocate alternative therapy such as TI [20]. Stent implantation and coil embolisation are complicated and expensive procedures that do not improve success rates and are therefore of only minor importance (in the groin region) $[2,8]$ Furthermore the area of femoral bifurcation appears unfavourable for the placement of covered stents because it's an area of flexion and the risk to occlude the deep femoral artery [3].

Anticoagulant medication favours persistence of a pseudoaneurysm and reduce the success rate of compression therapy [11]. Therefore TI should be considered as first choice in patients receiving aggressive anticoagulant therapy or dual antiplatelet therapy and also in patients who experience severe pain during compression [9]. Definitive duplex ultrasound imaging of the needle tip is essential when performing TI. Biopsy-line guided ultrasound is a useful option. Slow and fractionated injection of thrombin, correct positioning of the injection needle in the centre of the pseudoaneurysm and small dose of thrombin are recommended to avoid embolism. Special care of TI should be taken in patients with arterial occlusive disease. Other risk factors for distal embolism are thrombin dose, length of the aneurysm neck, age above 80 years and bolus treatment [12]. In our experience, symptomatic arterial embolism due to TI should treated urgently to reduce longterm side-effects. Invasive procedures such as surgery or thrombolysis should not be delayed. A 'wait and see approach' or conservative management as described in other studies should be viewed critically in symptomatic patients $[1,14]$.

\section{Conclusion}

When performed with adequate expertise, TI is a safe procedure with a high success rate. Advantages compared to surgery are a minimal trauma and the avoidance of general anaesthesia in multi-morbid patients which reduces postoperative risks and length of hospital stay. Indications for surgery are large pseudoaneurysm with compression of neighboring structures, neurological symptoms, hematoma-related skin maceration, failure of other therapeutic options and moreover local infection, rapidly expanding or ruptured pseudoaneurysms with active bleeding and instable patients.

\section{References}

1. Dzijan-Horn $M$, Langwieser $N$, Groha $P$, Bradaric $C$, Linhardt $M$, et al (2014) Safety and efficacy of a potential treatment algorithm by using manual compression repair and ultrasound-guided thrombin injection for the management of iatrogenic femoral artery pseudoaneurysm in a large patient cohort. Circ Cardiovasc Interv 2: 207-215.

2. Tsetis D (2010) Endovascular treatment of complications of femoral arterial access. Cardiovasc Intervent Radiol 3: 457-468

3. O'Sullivan GJ, Ray SA, Lewis JS, Lopez AJ, Powell BW, et al (1999) A review of alternative approaches in the management of iatrogenic femoral pseudoaneurysms. Ann R Coll Surg Engl 4: 226-234.

4. Thalhammer C, Kirchherr AS, Uhlich F, Waigand J, Gross CM (2000) Postcatheterization pseudoaneurysms and arteriovenous fistulas: repair with percutaneous implantation of endovascular covered stents. Radiology 1: 127-131.

5. Gehling G, Ludwig J, Schmidt A, Daniel WG, Werner D (2003) Percutaneous occlusion of femoral artery pseudoaneurysm by para-aneurysmal saline injection. Catheter Cardiovasc Interv 4: 500-504

6. Le Reste JY, Nabbe P, Rivet C, Lygidakis C, Doerr C, et al. (2015) The European general practice research network presents the translations of its 
Citation: Horn M, Stahlberg E, Goltz JP, Rodd C, Ellebrecht D, et al. (2017) Management of Groin Pseudoaneurysms: Indications and Outcomes for Thrombin Injection vs. Surgical Treatment. J Vasc Med Surg 5: 300. doi: 10.4172/2329-6925.1000300

comprehensive definition of multimorbidity in family medicine in ten European languages. PLoS ONE 1: e0115796.

7. Rowe VL, Lee W, Weaver FA, Etzioni D (2009) Patterns of treatment for peripheral arterial disease in the United States: 1996-2005. J Vasc Surg 4: 910-917.

8. Krueger K, Zaehringer M, Strohe D, Stuetzer H, Boecker J, et al. (2005) Postcatheterization pseudoaneurysm: results of US-guided percutaneous thrombin injection in 240 patients. Radiology 3: 1104-1110.

9. Schneider C, Malisius R, Küchler R, Lampe F, Krause K, et al. (2009) A prospective study on ultrasound-guided percutaneous thrombin injection for treatment of iatrogenic post-catheterisation femoral pseudoaneurysms. Int $\mathrm{J}$ Cardiol 3: 356-361.

10. Pezzullo JA, Dupuy DE, Cronan JJ (2000) Percutaneous injection of thrombin for the treatment of pseudoaneurysms after catheterization: an alternative to sonographically guided compression. AJR Am J Roentgenol 4: 1035-1040.

11. La Perna L, Olin JW, Goines D, Childs MB, Ouriel K (2000) Ultrasound-guided thrombin injection for the treatment of postcatheterization pseudoaneurysms. Circulation 19: 2391-2395.

12. Lewandowski P, Maciejewski P, Wąsek W, Pasierski T, Budaj A (2011) Efficacy and safety of closing postcatheterisation pseudoaneurysms with ultrasoundguided thrombin injections using two approaches: bolus versus slow injection. A prospective randomised trial. Kardiol Pol 9: 898-905.

13. Hofmann I, Wunderlich N, Robertson G, Kieback A, Haller C, et al. (2007) Percutaneous injection of thrombin for the treatment of pseudoaneurysms: the German multicentre registry. Eurolntervention 3: 321-326.
14. Paulson EK, Nelson RC, Mayes CE, Sheafor $D H$, Sketch $M H$, et al. (2001) Sonographically guided thrombin injection of iatrogenic femora pseudoaneurysms: further experience of a single institution. AJR Am J Roentgenol 2: 309-316.

15. Sheiman RG, Brophy DP (2001) Treatment of iatrogenic femoral pseudoaneurysms with percutaneous thrombin injection: experience in 54 patients. Radiology 1: 123-127.

16. San Norberto García EM, González-Fajardo JA, Gutiérrez V, Carrera S, Vaquero C (2009) Femoral pseudoaneurysms post-cardiac catheterization surgically treated: evolution and prognosis. Interact Cardiovasc Thorac Surg 3: 353-357.

17. Horn M, Kaczmarek PM, Zimmermann M, Hoffmann M, Hildebrand P, et al (2012) Treatment of the persistent Pseudoaneurysm: point of view of a vascular surgeon. (Our experience of ultrasound-guided thrombin injection and operative treatment). Gefäßchirurgie 17: 366-373.

18. Kent KC, McArdle CR, Kennedy B, Baim DS, Anninos E, et al. (1993) A prospective study of the clinical outcome of femoral pseudoaneurysms and arteriovenous fistulas induced by arterial puncture. J Vasc Surg 1: 125-131.

19. Paulson EK, Hertzberg BS, Paine SS, Carroll BA (1992) Femoral artery pseudoaneurysms: value of color Doppler sonography in predicting which ones will thrombose without treatment. AJR Am J Roentgenol 5: 1077-1081.

20. Luedde M, Krumsdorf U, Zehelein J, Ivandic B, Dengler T, et al. (2007) Treatment of iatrogenic femoral pseudoaneurysm by ultrasound-guided compression therapy and thrombin injection. Angiology 4: 435-439. 